\title{
EL “GLAMOUR” DE LA MARGINALIDAD EN ARGENTINA: CUMBIA VILLERA LA EXCLUSIÓN COMO IDENTIDAD
}

\author{
Luz M. Lardone*
}

\begin{abstract}
RESUMEN
Desde hace algo más de una década, la Argentina es testigo del surgimiento de un nuevo fenómeno musical: la cumbia villera, caracterizado por un ritmo irresistible y letras controversiales. El presente trabajo, investiga la cumbia villera como práctica cultural. Una manifestación discursiva y simbólica territorializada, de la lucha y la respuesta de la vida urbano marginal a las políticas neoliberales en América Latina. Este artículo determina esta práctica cultural como un drama sociopolítico, donde la identidad se construye desde los márgenes.
\end{abstract}

PALABRAS CLAVE: ARGENTINA * EXCLUSIÓN SOCIAL * CUMBIA VILLERA * IDENTIDAD * PRÁCTICA CULTURAL * GÉNERO MUSICAL * MANIFESTACIÓN SIMBÓLICA

ABSTRACT

For about a decade Argentina has witnessed the emergence of a new musical phenomenon: cumbia villera, characterized by an irresistible rhythm and controversial lyrics. The present work investigates cumbia villera as a cultural practice. A discursive, territorialized symbolic manifestation of the marginal urban life struggle and response to neoliberal policies in Latin America. This paper assesses this cultural practice as a socio-political drama where identity is constructed from the margins.

KEY WORDS: ARGENTINA * SOCIAL EXCLUSION * CUMBIA VILLERA * IDENTITY * CULTURAL PRACTICE * MUSICAL GENRES * SYMBOLIC MANIFESTATION

\section{ESBOZO DE UNA PRESENTACIÓN DE UN MISMO TODO CULTURAL}

Mucho se ha hablado y algo se ha escrito sobre la cumbia villera y quienes la cantan $y$ ejecutan. Se pueden encontrar posiciones que la mencionan como parte de "otro todo"; la atacan

Tesiaria de la Maestría Académica en Comunicación $y$ del Doctorado en Estudios de la Sociedad y la o enaltecen desde lo estético y musical; la interpretan desde lo sociopolítico y económico; la detestan desde el "buen gusto y mejores costumbres"; la analizan en un determinado contexto; la condenan por representar lo marginal; o la ensalzan porque, desde una hipócrita identificación de clases, pretenden mimetizarse con ella... 
Mientras, algunos la disfrutan. Parece haber tantas teorías como posiciones ideológicas desde donde abordarla. Tantas, que da la sensación de nunca poder terminar de abarcarla.

El presente trabajo procura indagar sobre la relación individuo-sociedad, circunscripta a grupos que comparten, conscientemente, un mismo universo simbólico —el lenguaje como elemento fundamental de la interacción-y asimismo, explorar cómo un elemento constituye al otro. Dicha aproximación teórica, aborda la cumbia villera desde el contexto socio histórico, donde la periferia urbana encuentra una de las múltiples formas de expresión. Porque, si las historias oficiales han sido construidas desde los discursos hegemónicos de supresión, la cumbia villera se presenta como una de las tantas formas no oficiales de leer la Argentina de la última década. Un ejemplo más de los ayuda memoria que podemos repasar para ver cómo desde los simbólico lingüístico, pero también desde lo presentativo, es decir lo no asociado con lo discursivo sino a los mitos, a los rituales, a los íconos, etc., se construye parte de la identidad.

La experiencia musical "villera", en su interacción dialéctica con el ambiente, permite entonces aproximarse a un producto cultural argentino de exportación, que se oye pero no siempre se escucha $y$ que se baila pero no siempre se decodifica en contexto. Una práctica cultural donde, como sostiene la letra de una canción folclórica popular argentina, "si se calla el cantor, calla la vida..." . Hoy, la cumbia villera nos dice, no sólo desde el lenguaje con sus símbolos significantes que, cuando se siente que no hay presente, ya no hay nada que perder... ni siquiera la vida. Así, desde la música que los identifica, los villeros acribillan con violencia a un destino inapelable que los escudriña cotidianamente. La cumbia villera, narra lo que la sociedad expulsa, y retoma en las páginas amarillas de los medios gráficos, los programas de más rating de la radio o la TV, las crónicas policiales, las fiestas o el análisis académico...

1 Canción Si se calla el cantor, del cantautor argentino Horacio Guaraní.

\section{EXPRESIÓN DEL MUNDO QUE SE HABITA}

Se parte de considerar a la cultura como el ámbito de producción, circulación y consumo de significaciones (García Canclini, 1991:28), pero distinguiendo dos tipos de producciones culturales: una que abarca los bienes simbólicos gestados en campos específicos o subsectores institucionalizados - el educacional, el de la ciencia y la tecnología, las industrias culturales, el artístico y el religioso-y en otro nivel, la cultura cotidiana donde se expresan y cumplen los procesos comunicativos de los campos $y$ se realizan las interacciones situadas entre los individuos y los grupos (Brunner, Catalán y Barrios, 1989).

Por lo tanto, se considerará a la cultura como un sistema significante, que permite la comunicación, reproducción y vivencia del orden social. No se trata sólo del conjunto de productos materiales de una sociedad, o de las constelaciones simbólicas que permiten adjudicar sentido a las prácticas sociales, se trata de ambos, de la estructura significante y el significado estructurante (Williams, 2001; 1994:95).

Más allá de cualquier enfoque al que se adhiera, la cumbia villera es una práctica cultural, y sus raíces no son sólo argentinas y ni siquiera de estos tiempos. Williams (1994), sostiene que las prácticas culturales, se configuran a partir de un entorno simbólico que no es ajeno al orden social constituido que las individualiza $y$ les otorga un carácter específico. Pero este orden social se hace evidente $y$ se experimenta, se legitima y se preserva, precisamente a través de las prácticas culturales.

En la cumbia villera como práctica cultural, hay quienes se animan $y$ hacen un paralelismo con el tango del arrabal; otros con el rock de protesta $y$ algunas manifestaciones culturales como los narcocorridos mexicanos, la cumbia colombiana, el swing criollo, el rap o el hip hop, y el reggae entre otros. Su lenguaje, como sostiene Olivier (2002):

... no es el del tango, ni el del rock, ni el de las primeras cumbias compuestas en la Argentina, pero incorpora fragmentos de todos ellos, $y$ hace de la coprolalia - la preferencia por las palabras agresivamente 
"sucias"-, su característica más notoria. (Comillas en el original).

Quienes la cantan y ejecutan, son jóvenes de los barrios más marginales de la Argentina, las villas $^{2}$. Ellos piensan y se expresan sobre el mundo social que habitan: ciudades hechas de estructuras humildes, al estilo de las favelas brasileras, los cantegrilles uruguayos, los tugurios costarricenses o los pueblos jóvenes peruanos entre otros. En el mejor de los casos, cuando no son casillas de cartón, las viviendas son una anarquía de ladrillos comunes, mucha arena $y$ un poco de cal. Un laberinto interminable de pasillos y calles de tierra, con la pobreza, la violencia y las drogas como escenario. Llamadas eufemísticamente villas de emergencia ${ }^{3}$, estos son los barrios en los que la policía preferiría no entrar, a no ser que tengan algún "negocio" pendiente.

En medio de las miserias de la villa, se esperaría que la música funcionara como un catalizador, un articulador de la experiencia de pobreza con la necesidad de modificarla, pero la mayoría de la cumbia villera parece útil, principalmente, para entretener y distraer. Como un

Las villas toman su nombre de la novela Villas Miseria también es América - Ed. Sudamericana- que en 1957 publicara el periodista Bernardo Verbitsky, donde se describen las condiciones de vida de los migrantes internos de la República Argentina durante la denominada Década Infame, que comienza en 1930 con el golpe de Estado contra Hipólito Yrigoyen, en el contexto mundial de la Gran Depresión.

Durante mucho tiempo, las villas se llamaron "villas miseria". En la actualidad el "miseria" no se usa, porque la miseria está implícita. Las autoridades las llaman "villas de emergencia", eufemismo que presupone que, cuando la emergencia pase, las personas vivirán en lugares más aptos. De esta manera, la Comisión Municipal de la Vivienda de la Ciudad Autónoma de Buenos Aires, denomina Villa de Emergencia a aquellos asentamientos ilegales de familias en tierras fiscales y en algunos casos de terceros particulares, habitando en construcciones que no cumplen normas mínimas edilicias o de habitabilidad e higiene, compatible con la vida urbana, configurando un alto grado de hacinamiento poblacional $y$ familiar.

Ver <http://buenosaires.gov.ar/areas/jef_gabinete/ vivienda/?menu_id=15970> narcótico, ayuda a olvidar el dolor y la lucha de la vida cotidiana. En su glorificación de la droga, el delito y el sexo, la versión villera de la cumbia, sustrae y desanima la participación e interés en asuntos políticos, donde no hay otro proyecto que defender más que la propia subsistencia (Narodowski, 2004).

\section{UN BREVE RECORRIDO HISTÓRICO POR LA SEMPITERNA PERIFERIA QUE SE EXPRESA Y CENTRA EXPECTATIVAS...}

A lo largo de la historia argentina, puede verse cómo han surgido actores sociales representativos desde las expresiones musicales marginales. Discursos que, al igual que la cumbia villera, mostraron el glamour de las periferias urbanas. Así, como si fueran imágenes secuenciadas de la historia y desde una dimensión temporal, el gaucho del folclore nacional argentino; el inmigrante y sus aportes a las fusiones de ritmos; el malevo o la pebeta del tango y el roquero "protestón" por nombrar sólo algunos, tanto como los cumbieros actuales, son partes fragmentadas de un mismo todo cultural, $y$ puede verse entonces cómo, experiencialmente, estos actores han podido comunicar su mensaje de vida.

Un menaje que, siendo parte de la comunicación humana - como una instancia de expresión del self (Mead, 1972)— le permite al individuo ser un objeto para sí mismo, es decir que al mismo tiempo que se afecta al interlocutor con lo que se dice, hay una afectación a sí mismo con lo dicho. Es también, a partir de la interacción, donde hombres y mujeres que - como intérpretes de su medio y de sus intersubjetividades - han explicitado y explicitan una conducta social que sólo puede ser entendida dentro del contexto de la estructura social en la cual toma lugar.

Sólo por tomar un punto de partida y desde una dimensión temporal, una expresión musical como el tango - el género más popular en el Río de la Plata durante la primera mitad del siglo XX-surge como el heredero directo de las primeras aglutinaciones de ideologías, prácticas, patrimonio cognoscitivo-lingüístico, historia, formas de ver el mundo que se manifiestan 
$y$ se hacen texto, discursos ${ }^{4}$. El tango - como la cumbia villera - le dio voz a quiénes no la tenían. El lenguaje tanguero de inmigrantes y criollos que rodeaban la ciudad de Buenos Aires, el lunfardo $o^{5}$, se introdujo lentamente en el habla cotidiana de los conventillos ${ }^{6}$, se hizo lenguaje

"La generación del 80" - y su proyecto de civilización o barbarie- como se llamó a los entonces gobernantes argentinos, con Sarmiento, Roca, la oligarquía agropecuaria y la europeización, fomentaron y contribuyeron la construcción de una identidad dislocada. Desde entonces, no todos los inmigrantes que llegaron al Río de la Plata "para hacer la América", —expulsados de las metrópolis europeas y atraídos por la necesidad de brazos para la tierra declarada por los gobernantes de entonces - lo consiguieron. A cambio trajeron su música, costumbres y sus idiomas entre otras cosas. Las generaciones posteriores, hijos directos de los irónicamente llamados por la historia oficial como "primeros pobladores", intentaron conquistar el sueño de sus padres desde la pobreza y la humildad. En un proceso de doble exclusión, muchos de los que llegaron, optaron por quedarse en Buenos Aires y la periferia porteña se gestó, impregnada de múltiples formas y sonidos. Las clases acomodadas de entonces, buscaron un lugar geográfico de diferenciación y, no por casualidad, fueron los barrios de la zona norte, los que demarcaron la territorialidad. Mientras tanto, en el sur y hacia adentro del país, convivían las expresiones culturales de los inmigrantes con manifestaciones locales, en pugna por la negociación de significados. Ver: Cerrutti, A y Pitta, C. "Los que bajaron de los barcos: migración ultramarina y prejuicio antiextranjero en la Argentina, 1880-1930”. En: Margulis, M. Urresti, M y otros (1998). La segregación negada. Cultura y discriminación social. Bs. As., Biblos. 1999.

El lunfardo, nació como un recurso para nombrar lo que debía quedar en secreto de alcobas, bares y cárceles. Ver: Barcia, P. L. Diccionario del habla de los argentinos. Academia Argentina de Letras. Bs. As., Espasa. 2003.

Los Conventillos eran casa aristocrática o importante por sus dimensiones y riquezas, convertidas en casa de vecindad, también conocida como inquilinato. Muchas veces, el conventillo representaba el uso tardío de casas residenciales o petit hotels en vecindarios que habían descendido de categoría social. Solían presentar malas condiciones sanitarias producto del hacinamiento. En Argentina fue el primer hogar de muchos inmigrantes recién llegados al país donde se usual para hablar entre hombres, se enriqueció en la cotidianeidad y llegó a transformarse en marca identitaria de lo argentino (Salas, 1996). Con el aluvión zoológico ${ }^{7}$ y durante el primer gobierno de Juan D. Perón (1946-1951), aparece la cumbia como género musical. La historia se repitió entonces con los cabecitas negras $^{8}$ que migraban internamente. Quienes no encontraron las prometidas oportunidades de la sustitución de importaciones que permitirían la industrialización nacional, ensancharon los cordones de pobreza de las grandes ciudades. Así, en la década del ' 50 , confluían y se fusionaban ritmos y estilos del interior del país y el incipiente desarrollo de la cumbia, como nuevo ritmo, se instalaba en Buenos Aires, sobre todo, en el primer cordón industrial conocido como Gran Buenos Aires.

Hacia 1960, las preferencias musicales argentinas parecían dividirse según las clases sociales y las procedencias geográficas: obreros $y$ trabajadores de clase baja se inclinaban por la

mezclaban idiomas, culturas y nacionalidades. De allí, surgirían el tango y el sainete como pieza dramática jocosa de carácter popular. Hoy, se ha resignificado el viejo conventillo puesto que persisten las razones que motivaron su aparición. Son entonces las casas tomadas donde, hacinadas, malviven familias enteras. Ver: Szwarcer, C. "El Conventillo de la Paloma un siglo después". Revista Cultural del CECAO. Año II, nro. XIX, mayo del 2004, Córdoba, Argentina.

$7 \quad$ Aluvión zoológico, es la expresión que usó el diputado radical Ernesto Sanmartino, para designar a la gran migración que se produjo desde el interior de todas las provincias argentinas hacia Buenos Aires. Miles de personas recalaban en espacios urbano marginales (como conventillos, pensiones 0 , en el mejor de los casos, humildes barrios obreros de los polos de desarrollo industrial de la época. Con la expresión aluvión zoológico, se produce un desplazamiento del objeto de aversión, mediante una caracterización no humana, provocando así, una animalización de lo popular.

8 Luego del triunfo de Juan Domingo Perón, se produce una migración interna donde muchas personas se trasladaron masivamente del campo a la ciudad. A estos nuevos actores sociales se los llamó Cabecitas negras. Ver Rozenmancher, G. Cabecita Negra. Bs. As. De La Flor. 1997. 
cumbia tradicional y el folclore, mientras los jóvenes de clase media consumían rock importado impulsado por las multinacionales discográficas. En ese entonces, podría decirse que la cumbia actuaba como "asilo virtual" para trabajadores de bajos ingresos.

Durante el Proceso Militar de Reorganización Nacional (1976-1983), no hay más que silencio, censura, exilio y muerte. La clase media argentina perdió el espacio público, un lugar de contacto que fue sustituido por el interior de las viviendas para evitar la violencia de estado. Las principales víctimas fueron los jóvenes, $y$ con ellos se acallaron coercitivamente muchas voces aunque, el rock de protesta pudo camuflarse y cantar las injusticias de la represión del estado. No obstante, cabe señalar que es precisamente bajo la dictadura militar, en los años '70, cuando aparecen en el Gran Buenos Aires, las primeras bailantas ${ }^{9}$, grandes galpones muy simples destinados a la música "tropical", que competían con las peñas, reservadas al folklore nacional.

Luego, vino por fin, la ansiada democracia (1983) y con ella, una explosión casi extremista de la libertad de expresión, pero los excesos quedaban desfigurados ante la recuperación de algunos derechos básicos. En los medios masivos de comunicación, la cumbia argentina hacía su aparición. El primer programa de radio dedicado a la cumbia se oyó en 1986, en Radio Splendid, un espacio abierto con el objetivo de promocionar grupos de música tropical que no encontraban cabida en el circuito mediático masivo de entonces.

La década del '90 fue sin duda de cambios. Durante la debacle socio político y económica del Menemismo (1989-1999), donde todo era una "fiesta" y una peligrosa puesta en escena, la cumbia "de barrio" irrumpió con fuerza.

El término bailanta tiene múltiples acepciones y proviene de una fusión idiomática. Generalmente se le utiliza para denominar el lugar donde se baila música tropical. Ver: Academia Porteña del Lunfardo. Acerca del término bailanta. Comunicación Académica Nro. 1541. Bs. As., abril del 2001. En: <http://ar.geocities.com/ lunfa2000/1541.html>
A diferencia de la cumbia tradicional más "romántica", esta comenzó a reflejar las vivencias de los sectores más marginados de la sociedad. Como un emergente de la decadencia en que estaba inmersa la sociedad argentina, las instituciones, el descrédito en la corrompible clase política, etc., la cumbia tradicional se territorializaba (Danesi, 2000:178) ${ }^{10}$ en las villas miseria. Presentándose como expresión cultural periférica, apropiada y resignificada desde los medios de comunicación en los nuevos viejos tiempos modernos ${ }^{11}$, la cumbia villera surgía,

10 En el capítulo 10 de su libro Sign, Thought and Culture, Marcel Danesi presenta la semiótica del espacio y define la territorialidad. Apelando al término proxemics acuñado en 1966 por el antropólogo E. Hall, se refiere al estudio de los aspectos culturales, comportamentales y sociológicos de las distancias espaciales entre los individuos y el demarcar los límites de sus territorios. Danesi, M. (1988) Sign, Thought and Culture, $2^{\circ}$ ed., Toronto, Canadian Scolars' Press. 2000.

11 Nuevos viejos tiempos modernos es la denominación que se adopta para la etapa histórica que estamos viviendo, $y$ que otros autores han definido específicamente. Distintas perspectivas que, entre otras, contemplan desde la desapropiación donde el capital borra espacios y tiempos en realidades planetarias (Harvey, D. La condición de la posmodernidad: investigación sobre los orígenes del cambio cultural. Amorrortu, 1998); pasando por un enfoque económico acerca de los condicionantes infraestructurales (Lyotard, J. F. La condición posmoderna-Informe sobre el saber, $6^{\circ}$ ed., Cátedra, Madrid. 1998); o lo que queda cuando el proceso de modernización ha concluido en el capitalismo tardío (Jameson, F. "Teoría de la postmodernidad". Trotta, Madrid, 2001 y "El postmodernismo o la lógica cultural del capitalismo tardío". Revista Casa de las Américas. Nro. 155-156, pp. 141-173. 1986); hasta la propuesta de modernidad inacabada (Habermas, J. "Modernidad versus Posmodernidad", en Pico, J. (ed) Modernidad y Postmodernidad, Madrid, Alianza, 1994, pp.87-103), etc. El concepto nuevos viejos tiempos modernos surge entonces de considerar que la modernidad no es tardía, ni inacabada sino que se ha resignificado en tiempos de capitalismo tardío. Esta construcción, permite amalgamar distintas posiciones teóricas con el objeto de significar que: el proyecto moderno se ha cumplido pero, sólo en partes. En consecuencia, dará cuenta de esa modernidad resignificada. 
pública y masivamente, bajo el rótulo comercial de movida tropical ${ }^{12}$.

\section{MACROENTORNO DE LA CUMBIA VILLERA}

La cumbia villera, no es espontánea. Como síntoma emergente de la exclusión y la marginalidad, es el surgimiento de otra forma de expresión y no de una nueva forma de expresión porque, en América Latina, la exclusión y la marginalidad tienen desde siempre, como sostiene Carlos Sánchez Ocampo (2003) rostros mixtos y mutantes.

Desde esta perspectiva, podría sostenerse que la base neoliberal de la globalización, ha reconfigurado los bordes sociales y necesita más que nunca de los "otros". La idea económica o financiera del "planeta globalizado" encierra, entre muchos peligros, el de aceptar que para que algunos accedan a los "beneficios" del desarrollo, se hace necesario que otros vivan en condiciones de miseria inaceptables (Barker, 2003:99) ${ }^{13}$. Un proceso desigual y polarizado, que no implica necesariamente la globalización de la cultura.

Pero, la globalización, no puede ni debe verse como un proceso autónomo que impacta en las culturas, $y$ que estas pasivamente reciben sus consecuencias. Paralelamente a la globalización económica, en los países dependientes, parecen haberse revitalizado procesos de resistencia que reafirman identidades y cargan, simbólicamente,

En la cumbia argentina, se diferencian varios estilos asociados a su procedencia geográfica: el norteño (Santiago del Estero, Formosa, Tucumán, etc.), el cordobés (Córdoba), el santafecino (Santa Fe), entre otros. Las últimas variantes que se han desarrollado, se identifican como rapera, de barrio o villera. Así, la cumbia en todas sus variantes, y el cuarteto — ritmo característico de la provincia de Córdoba, se conocen de manera general como movida tropical.

13 Barker ha argumentado que la economía del mundo occidental, posterior a 1945, ha estado dominada por el FORDISMO como praxis económica, y por el Keynesianismo como política económica de los estados nacionales. Juntas, ambas prácticas significan más que una estrategia económica, sino que constituyen principios organizacionales $y$ las relaciones culturales de la formación social en su integridad. Barker, C. (2000) Cap. "A New World Disorder". En: Cultural Studies. Theory and Practice.. Londres, SAGE Publications, pp. 99-100. 2003. aspectos diferenciados de su cultura. Porque la identidad y la cultura no pueden disociarse de un contexto social determinado, el "nosotros" globalizado invocado por Giddens en Consecuencias de la Modernidad (1997:27) es, en realidad y aunque se pretenda la homogeneización, el "nosotros" de las grandes metrópolis, del mundo desarrollado, aunque en las sociedades de los países en vías de desarrollo exista una alianza tácita por parte de los segmentos más cosmopolitas o "progresistas".

Producto de la pretendida homogeneización, el mapa cultural de América Latina se transforma (Barbero, 2003), y la Argentina no es la excepción. Así como se desdibujan las fronteras nacionales, hacia el interior de los países el desplazamiento poblacional del campo a la ciudad no es meramente cuantitativo, es

... el indicio de una trama cultural urbana heterogénea, formada por una densa multiculturalidad, que es heterogeneidad de formas de vivir y de pensar, de estructuras del sentir y de narrar... (Barbero, 1997:19).

La cumbia villera entonces, le pone ritmo $y$ voz a esa multiculturalidad que se expresa desde lo urbano marginal argentino, resiste, $y$ parece evidenciar los cambios de fondo en la pertenencia al territorio $y$ la identidad, en un juego perverso de inclusión/exclusión.

\section{CONTEXTO DE LA CUMBIA VILLERA: LA MARCA SOCIAL DE LOS "VILLEROS"}

Desde una dimensión espacial, las villas miseria de la Argentina, son mucho más que conjuntos de casas hechas de materiales precarios o "conglomerados humanos". En su mayoría, se han nutrido y se nutren de los expulsados de las economías regionales con sus expectativas centradas en la ciudad. Son, como tantos suburbios de los grandes centros urbanos de América Latina, producto de estos nuevos viejos tiempos modernos en el capitalismo tardio (Jameson, 1986). Periferias donde la desocupación no es masiva, pero abunda - en el mejor de los casos- el empleo informal. Las familias crecen hasta rozar el hacinamiento, mientras el acceso a los servicios 
básicos suelen encontrar límites no sólo en la pobreza, sino también en la estigmatización por vivir en la villa. Pertenecer a una villa miseria, es relevante en términos de identidad social, puesto que sus habitantes son actores sociales percibidos desde un conjunto de categorías que no les son propias, sino construcciones externas.

Arquitectónicamente, las características urbanísticas de la villa la distinguen del entorno. Prácticamente no tiene calles centrales que permitan la circulación de vehículos: entre las casas hay pasajes y pasillos habilitados para uso interno. Hay hacinamiento y roces que generan chispas. Una conformación que posibilita una fuerte identidad de pertenencia al lugar, $y$ un espacio de actividad endogrupal. Hacia afuera, es un reducto bien diferenciado que permite darle una precisión geográfica a la exclusión. Una marca identitaria opuesta a la impersonalidad $y$ el anonimato que caracteriza a las grandes ciudades como Buenos Aires. La propia configuración sitúa a la villa como un entorno que se percibe peligroso, contrapuesto al "otro entorno", al que es construido desde la "arquitectura de la seguridad" como refugio ante los efectos de la marginalidad que los rodea.

Asociados a la delincuencia en sus formas más variadas $y$ al consumo y comercialización de drogas, los habitantes de las villas, llegan al extremo de la exclusión por el sólo hecho de pertenecer a un espacio público diferente al resto de la ciudad. Un espacio donde los bordes se pueden achicar casi hasta la asfixia. Cuando se acepta el discurso externo, se localiza la exclusión en un "otro" del que no se es parte. Así, para definir lo que se considera propio, se exageran las diferencias con los que están afuera, con los otros significantes (Larraín Ibáñez, 1996:91).

En la internalización del discurso externo que los rechaza, los villeros buscan diferenciarse, a tal punto que se demandan justificaciones de las transgresiones entre los "elementos" internos, pero a la vez externos de la villa: inmigrantes peruanos - llamados despectivamente perucas-, bolivianos - "bolitas"-, paraguayos — "paraguas"-, y hasta dominicanos entre otros, porque se necesita encontrar responsables de las "malas prácticas". Representaciones hacia adentro y desde fuera $y$, si bien se entiende que todas las representaciones significan una simplificación de lo representado, son fundamentales para la construcción del orden simbólico y esenciales para la construcción de subjetividades (Rodríguez, 2003). Al respecto, Sandoval (2002: 7-9), refiriéndose a la construcción de imágenes de la "otredad", sostiene que:

La representación de ciertos grupos como 'otros' se elabora a través de la articulación de imágenes de diferencia, las cuales en ocasiones remiten a imágenes racializadas, pero también a referencias de género o clase, principalmente. El "otro" es el que (...) nombra la realidad externa más allá de sí mismo (...). Un sentido de sí mismo que es constituido a través de la expulsión de atributos indeseables presentes en la propia comunidad.

La autorepresentación positiva de algunos $y$ la representación negativa de otros, parece ser una propiedad fundamental de las formas sociales de estigmatización. Así, en los crecientes procesos de exclusión de la Argentina de hoy ${ }^{14}$, los numerosos $y$ diversos grupos de excluidos $y$ estigmatizados, desarrollan nuevas formas culturales, articulando las identidades necesarias para sobrevivir en condiciones de carencia, privación y desigualdad. La cumbia villera aparece entonces, como relato musicalizado de lo urbano marginal argentino.

Según el Instituto Nacional de Estadísticas y Censos de la Argentina - INDEC - para el segundo semestre del 2005, casi el 35\% de la población vive por debajo de la línea de pobreza. Es decir, alrededor de 13 millones de habitantes - sobre una población de más de 36 millones según el último censo de 2001- Las valoraciones estadísticas del INDEC, señalan que esos 13 millones de habitantes bajo la línea de pobreza, viven en hogares que no tienen ingresos suficientes para compra de la canasta básica de bienes y servicios. Además, un millón y medio de personas (el 10,1\%) están incluidas en las valoraciones estadísticas de desempleo a nivel nacional, lo cual implica que hay un millón y medio de desocupados. Ver: Instituto Nacional de Estadísticas y Censos http://www.indec.mecon.ar/ Incidencia de la pobreza e indigencia en 28 conglomerados urbanos. Segundo semestre 2005. En: <http://www.indec.mecon.ar/ nuevaweb/cuadros/74/pob_tot_2sem05.pdf> 
Es la villa y su cotidianeidad, quienes enmarcan la temática de la cumbia villera: hábitos, estructuras, normas y modos de expresión propios. Un complejo rompecabezas multidimensional de acciones e interacciones sociales, textos, lenguajes, jergas y estilos. Podría decirse que es el glamour de la pobreza que brota gozoso... Un goce difícil de comprender desde otros sectores sociales.

\section{CUMBIA VILLERA: "LAS PALMAS DE TODOS LOS NEGROS ARRIBA Y ARRIBA..."}

Ante los sentidos, todo parece igual: ritmo $y$ vestimentas, número de integrantes, pasos de baile, instrumentos y "calidad musical". Cuando los grupos son reconocidos, pueden llegar a presentarse hasta en 5 ó 6 bailantas por noche. Jóvenes con pianos portátiles colgados en el cuello, ropa deportiva de marca internacional, modos particulares de hablar, caminar y saludarse... Mariano Narodowski (2004) sostiene que "La cumbia villera ayuda a la construcción de una estética vinculada a los pobres, sus vidas, su trabajo, su sexo, su cuerpo, sus adicciones”.

Habitualmente, se repite la misma fórmula: el líder del grupo sale al escenario y antes de saludar, inicia su actuación diciendo: "Las palmas de todos los negros arriba y arriba...", simulando un robo a mano armada. Inmediatamente todos comienzan a gritar y levantar las manos al ritmo de la música. Se busca afianzar y ritualizar la pertenencia. Luego, se incorporan expresiones como: "El que no salta es un cheto...". (alguien de la clase alta). "El que no salta es un careta..." (que no consume drogas) "El que no salta es...". Se refuerza la idea sobre quienes no son como los que están allí, quienes no comparten los códigos e ideales. Una construcción por oposición, casi como un enemigo.

Concebida la sociedad como lo hace Habermas en su Teoría de la acción comunicativa (1989:493), es decir desde la perspectiva de un sujeto en acción, donde dicha acción se traducen en manifestaciones simbólicas y donde el actor entra en relación al menos con un mundo - siempre con el mundo objetivo-, la cumbia villera parece ser un ritual que manifiesta y legitima un modo de vida, en el que sus portavoces adquieren conciencia social.
Una conciencia concebida como procesual-social que se va construyendo en la interacción (Mead, 1972), donde sus intérpretes y seguidores tiene acceso privilegiado ${ }^{15}, y$ donde la identidad villera surge entonces como algo que sólo tiene sentido en la vida grupal, en la vida con los otros ante quienes se presenta a través de la música, $y$ que esos otros retroalimentan.

Como sostiene Auyero (1993), la identidad social —en tanto percepción que un grupo tiene de su posición social-, se construye y representa en relación con los "otros", y esta "otredad" necesita ser construida y reconstruida permanentemente por los propios actores sociales. El contenido de las canciones villeras permitirá entonces que el sí mismo (self) villero no se relacione consigo al convertirse en objeto de sí, sino al reconocerse en el objeto externo, ya se trate de esquemas de acción o de simbolización.

En lo que respecta a la comunicación comunión- que se entabla con el público, Habermas (1989) diría que el hablante y el oyente se entienden desde y a partir del mundo de la vida que les es común ${ }^{16}$, — porque está simbóli-

15 Mead, rechazó la separación entre conciencia y sociedad - contexto social-. A través del concepto de self los individuos tiene conciencia y esta se va construyendo en la interacción social. En el interaccionismo simbólico propuesto por Mead, la conciencia tiene al menos dos significados distintos: uno que hace referencia a la subjetividad, donde sólo el actor social tiene acceso y otro, asociado al modo de pensar el mundo social que se habita. La conciencia es entonces procesual social, situada en el mundo objetivo donde se ubican los actores sociales. El lenguaje tiene un papel fundamental en la emergencia y la constitución de la realidad social $y$ los actores sociales surgen en un contexto pero son en sí mismas una construcción y estructura social. Mead, (1934) Espíritu, persona y sociedad. Bs. As., Paidós (3ºd.) 1972.

16 Habermas contempla la acción comunicativa y el mundo de la vida como conceptos "complementarios". El supuesto de la teoría de la acción comunicativa es que, existen tres mundos, los que constituyen conjuntamente el sistema de referencia que los hablantes suponen en común en los procesos de comunicación. El mundo externo alude a los mundos objetivo y social, $y$ el interno al mundo subjetivo. Es decir que, para esta concepción, el hablante, al ejecutar un acto de habla, entabla una relación pragmática con: - -algo en el mundo objetivo (como totalidad de las entidades sobre las que 
camente estructurado- sobre algo en el mundo objetivo, en el mundo social y en el mundo subjetivo. De manera que, entender un acto de habla, significa, saber qué lo hace aceptable —en cuanto a cumplir las condiciones necesarias para que el oyente pueda adoptar una postura afirmativa ante la pretensión que a ese acto vincula el hablante-, puesto que la acción comunicativa se basa en el consenso simbólico.

A través de su lenguaje, la cumbia villera se facilita la toma de conciencia como interiorización de procesos sociales que permite conocer a los otros y a sí mismo. Entonces, a manera de puente entre los individuos y la sociedad, en la cumbia villera puede verse cómo el self villero surge del contacto con la realidad social y cómo este self organiza esa realidad —el otro generalizado-. Es decir, cómo se conoce el orden social y se lo afecta por medio de la creatividad del "yo".

\section{BORGES AFIRMÓ: "LA GENTE ES COMO HABLA"}

Si una de las formas en que se materializa el lenguaje es el habla, constituyendo una actividad socio-discursiva y por lo tanto cultural, entonces la cumbia villera es capaz de hablar de la cultura y sus discursos. Voloshinov (1992:43) diría que:

son posibles enunciados verdaderos); o - algo en el mundo social (como totalidad de las relaciones interpersonales legítimamente reguladas); o —algo en el mundo subjetivo (como totalidad de las propias vivencias a las que cada cual tiene un acceso privilegiado y que el hablante puede manifestar verazmente ante un público), relación en la que los referentes del acto de habla aparecen al hablante como algo objetivo, como algo normativo o como subjetivo. Sin embargo, Habermas no sugiere que todo acto de habla sea o deba ser a la vez verdadero, recto, veraz, adecuado e inteligible. Trata de establecer que todo acto de habla presupone tales pretensiones. Cuando alguna de ellas resulta problematizada se da lugar a una específica forma de comunicación: el discurso argumentativo, cuya función es restablecer la acción comunicativa entre los hablantes, resolviendo el cuestionamiento de una determinada pretensión de validez. Habermas, J. Teoría de la acción comunicativa II: La construcción del mundo de la vida. Buenos Aires, Taurus, 1992.
La palabra penetra prácticamente en cuanta interacción e interrelación se lleve a cabo entre los hombres: en la cooperación en el trabajo, en los eventuales roces cotidianos, en las relaciones políticas, etc. En la palabra se ponen en funcionamiento los innumerables hilos ideológicos que traspasan todas las zonas de la comunicación social. Por eso es lógico que la palabra sea el indicador más sensible de las transformaciones sociales, incluso de aquellas que van madurando, que aún no se constituyen plenamente ni encuentran acceso todavía a los sistemas ideológicos ya formados y consolidados.

El lenguaje crea imágenes de lo real y concretiza los modos en que la sociedad refuerza o modifica sus representaciones de mundo. La realidad es también una construcción - una significación imaginaria, dice Castoriadis (1987) - es decir, que está dotada de sentido para los sujetos. Referencias a temas, tales como: las drogas, el alcohol, la falta de respeto a la autoridad, adoración a personajes polémicos... siempre existieron en la música surgida de la periferia. Sin embargo, las referencias se hacían con sutileza. La cumbia villera en cambio, las aborda en forma directa, sin eufemismos y con una buena carga de ironía casi violenta. Pero, la polisemia, la decodificación y la recepción de los mensajes, provocarán una interrogación sobre el sentido, según se trate de las diferentes subculturas de la estructura social, o se realice de manera individual o colectiva.

El público de la cumbia villera lo integran no sólo los habitantes de las villas. El "gran público" se completa con los otros, individuos de clase media $y$ alta que, sin cuestionar demasiado, la bailan en cualquier ocasión de festejo o la usan para tener más rating en sus programas de radio o TV en la sociedad del espectáculo ${ }^{17}$ (Debord,

17 En 1967, Debord publicó La societé du spectacle, en la que denuncia la mutación que el capitalismo hace del pensamiento por el espectáculo, como sustrato ideológico de dominación. El espectáculo crea un presente perpetuo apoyado en el espejismo de la tecnología, en el que es posible la ocultación, el simulacro, la mentira. La ficción y la apariencia toman la delantera a la realidad. En definitiva, la inversión de la vida. Debord, G. (1967) La sociedad del espectáculo. Castellote, Madrid. 1976. 
1976). Porque, el discurso de la cumbia villera es aceptado en los sectores sociales medios y altos, pero a manera de música carente de seriedad que invita a la alegría, a la diversión que en latín —divertere - significa alejar.

[Unos dirán] Eso no es música. No tiene la elaboración que tienen otros géneros musicales. [Otros, afirmarán que]: La cumbia villera está cargada de mensajes que atentan contra normas básicas de convivencia de una sociedad. Las letras hablan de drogas. Son machistas y groseros. [Habrá quienes sostengan que en la] movida tropical hay mafia o hasta el lacerante: Es cosa de negros...

A continuación, se presentan algunas letras y su explicación (parcial):

LETRA
Grupo Jalá Jalá
Maquina Jalá jalá
Chau loco zafá de acá
Voy a buscar la vagancia, en coche nos fuimos a un banco
y le metimos caño la plata y un rehén nos llevamos.
Nos sigue la policía un tiroteo grande se está armando,
pero tenemos un piloto que acelera y acelera y pasa
cambios.
Nos escapamos de la gorra y un tiro logran pegarnos.
Soltamos al rehén y la plata nosotros deliramos.
Seguí pasando cambios, pasá.
Nos compramos una flor de piedra, yerba brava para
fumar, mala fama tenemos en el barrio,
las damas gratis vienen y van.
Nos compramos una flor de piedra, yerba brava para
fumar, mala fama tenemos en el barrio
y a full queremos estar.
Y esto es Jalá Jalá

Gedientos del Rock

"Cumbia Gedienta"

¿Qué vamos a hacer? a Geder

Levantando las manos, que de gira nos vamos. Vamos a bailar, vamo a scaviar, levanten las manos de aquí para allá. Vamos a bailar vamo a tomar, levanten las manos de aquí para allá. Empezó la fiesta hay que bailar, esta cumbia gede pa gozar, levanten las manos para acá, levanten las manos para allá.

Tomamo una birra por acá, tomamo unos vinos por allá Esta cumbia gede hay que bailar y de la cabeza vamo a estar.

\section{Reempachados}

"Corazón"

Mi cabeza me da vueltas, que limado estoy.

Si no pinta una línea, el bajón a mi me mata y ni un vino me levanta, no coordino jllamen al doctor! Cuando yo no tomo nada, muy inquieto voy $y$ lo único que quiero es un facito.

Mi vieja un día a mí me aconsejo, nene vo no tomes nada, eso te hace mal a vos.

Solo soy un fumanchero y tengo alma de drogón es que hay algo en esa tuca que me gusta, que me gusta y re loco quedo yo.

Ya no aguanto sin un pase, no me aguanto más, si no pinta una línea, el bajón a mí me mata y ni un vino me levanta, no coordino, jllamen al doctor!...

Solo soy un fumanchero y tengo alma de drogón

es que hay algo en esa tuca que me gusta, que me gusta y re loco quedo yo...
EXPLICACIÓN (PARCIAL)

No hay nada que perder. ..

Se hace una apelación directa a inhalar cocaína. Luego, se relata la organización y el desarrollo de un asalto a mano armada, con toma de rehén, en un banco.

Interviene la policía, se desata un tiroteo en plena persecución policial. Se destaca la "calidad" del conductor del vehículo.

Se coquetea con la muerte que los hace sentir vivos.

Logran escapar de la fuerza pública, liberan al rehén y salen a gastar el botín obtenido.

Con el dinero compran una gran cantidad de cocaína y marihuana. Aseguran no ser bien vistos en el lugar donde viven pero las mujeres están con ellos sin cobrar. (Flor de Piedra, Yerba Brava y Damas Gratis, son nombres de grupos de cumbia villera)

Quieren estar a full.

Gediento significa hedor, mal olor, rechazo.

Salir a provocar hedor porque van a divertirse, a consumir alcohol y cocaína.

Desde el hedor van a disfrutar para gozar. Las manos arribas simulan el momento de un asalto.

Cerveza $y$ vino para estar bien, aturdidos.

Esta cumbia apesta, dicen...

La cabeza le da vueltas porque consume estupefaciente.

Tiene que encontrar cocaína, porque no soporta el síndrome de abstinencia y ni siquiera el vino lo ayuda. Se descontrola y entonces necesita que lo ayuden con su necesidad.

Cuando no consume necesita por lo menos un cigarrillo de marihuana.

La madre lo aconsejó pero... reconoce fumar marihuana habitualmente y ser drogadependiente que está pasado un mal momento. 


\begin{tabular}{|c|c|}
\hline LETRA & EXPLICACIÓN (PARCIAL) \\
\hline $\begin{array}{l}\text { Yerba Brava } \\
\text { "Pabellón" } \\
\text { Y con los ojos entreabiertos suelo descansar, y cuando } \\
\text { apenas casi duermo sueño mi libertad. ¡Cumbia villera! } \\
\text { Las marcas que tengo en la piel, las llevo en el alma, } \\
\text { en la mente también. Las llevo en el alma, en la mente } \\
\text { también. } \\
\text { La vieja me hizo entender, que acá en la tumba no se } \\
\text { duerme bien. Sufrió mi viejita mi encierro también. Al } \\
\text { pabellón, cuando yo vuelva, y empiece a gozar mi libertad } \\
\text { juro por lo que mas quiero que vuelvo a recuperar la } \\
\text { dignidad } \\
\text { ¡Denme otra oportunidad! }\end{array}$ & $\begin{array}{l}\text { Descansar con los ojos entreabiertos en la cárcel -la } \\
\text { tumba- porque no se confía en nadie, una vez entregado } \\
\text { al sueño, piensa en la libertad. A los presos se los llama } \\
\text { "tumberos" porque estar allí es como estar muertos. } \\
\text { En los códigos carcelarios, los presos se tatúan el cuerpo, } \\
\text { cuantos más tatuajes tienen, más evidencia de resistencia. } \\
\text { Generalmente es una cruz con puntos a los costados, } \\
\text { simulando una T. esas mismas marcas las tiene en la } \\
\text { psiquis. } \\
\text { Cuando salga de la cárcel va a recuperar la dignidad y para } \\
\text { ello pide otra oportunidad en la vida. }\end{array}$ \\
\hline $\begin{array}{l}\text { Grupo Kalú } \\
\text { "Haceme un pete" } \\
\text { Haceme un pete, haceme un pete. Que esta noche quiero } \\
\text { gozar. Me comentaron que esa chica hace unos petes } \\
\text { espectacular. }\end{array}$ & $\begin{array}{l}\text { Alusión directa a la sexogenitalidad oral y la mujer como } \\
\text { objeto sexual y de cambio. }\end{array}$ \\
\hline
\end{tabular}

Las letras de la cumbia villera apelan directamente a bebidas alcohólicas, sexogenitalidad oral y anal, términos catalogados como obscenos, delincuencia, fuga, delación, traición y policía entre otros. Identifican de igual manera a la prisión, como la muerte o el matrimonio. Códigos y frases de jóvenes marginales que se juntan en cualquier esquina a tomar cerveza $y$ hablan sobre las drogas, el sexo, la policía, la violencia, la discriminación o el fútbol... Entonces, el ámbito privado se hace público. En lo público se prostituye lo privado. En el contenido de las letras, se puede ver la relación individuo-sociedad: cómo un elemento constituye al otro y viceversa. Voloshinov sostiene que no hay experiencia fuera del lenguaje, "no hay vivencia fuera de la encarnación sígnica" (citado en Sandoval, 2002: 25).

También, en la cumbia villera se lleva el discurso falogocéntrico a su máxima expresión. Se describe a las mujeres jóvenes como prostitutas y/o ninfómanas, nunca son "compañeras". 0 son "las pibas" - femenino de los pibes-, y en ese caso son cómplices asexuadas y homologadas a los hombres, u objetos sexuales. Se legitima el descontrol sexogenital como supuesta liberación, ratificando la predominancia masculina por sobre el "uso de la mujer" como simple objeto. Podría profundizarse el análisis sobre el rol de la mujer en la cumbia villera, pero excedería el propósito de este trabajo. Sólo sostendré que, el mensaje de la cumbia villera, responde a identidades binarias de género, donde no hay cabida para lo múltiple. Perpetúa así, la identificación de género individual y exclusivo, $y$ refuerza lo binario jerárquico (Benjamin, 1996:225-230).

Los grupos sociales altos que consumen cumbia villera, toman distancia de las letras $y$ sus mensajes. Para ellos, el que canta es otro que no tiene punto de contacto. Un extraño que vive otra realidad muy alejada. Así, en constante ida $y$ vuelta, el aparente rechazo resulta funcional a quienes ostentan el simbolismo de la marginalidad, un simbolismo que, sin el rechazo, carece de sentido. Una de las posibilidades que la cumbia villera ingrese en ámbitos propios de clase media y/o alta, es a través de los medios de comunicación donde se simula la horizontalización de la cultura y así, la villa se integra virtualmente al resto de la comunidad.

\section{DE LA VILLA A LA PANTALLA DE TV: CONSUMO CULTURAL, ESPECTÁCULO DE LO MARGINAL Y CELEBRIDADES VILLERAS}

Los medios de comunicación, como agentes culturales constructores de sentido, acercan — distanciada y mediáticamente- la cumbia villera. Se convierte entonces, en música de divertimento sin distinción de clases ni espacios $y$, tanto la vestimenta como las posturas, el 
lenguaje, sus ídolos, etc., se comercializan como "moda", transformando la música del oprimido en diversión del frívolo. El sistema devuelve los símbolos metamorfoseados en mercancía neutralizada, ineficaz para servir al cuestionamiento social. El discurso del marginado pasa a segundo plano para priorizar las ganancias de los inversionistas.

No por casualidad, la denostada expresión villera se convierte en un muy buen negocio para los medios de comunicación masiva, especialmente para la televisión. Un cambio de actitud que los índices de audiencia - rating - testifican: lo que ayer había sido un símbolo de lo marginal, pasa a estar de moda y luego, será objeto de nostalgia y descarte. El artista villero pasa así de "rebelde" a cantante "fashion" y, luego, se convierte en un producto que "ya fue". A modo de ejemplo, en la actualidad $y$ desde hace varios años, cada sábado de 12 a 16:30 hs. por América 2 - uno de los canales de TV de aire de la Argentina, cuya señal llega no sólo a todo el país, sino también a algunos países de América Latina se presenta Pasión de sábados. Cuatro horas y medias de "ritmos tropicales", que se emite desde Buenos Aires.

Luego del olvido o en la cima de su éxito, los medios de comunicación, también considerarán a los "Villa Stars" como presas del escándalo. Los ídolos que caen ante la ley, son "rescatados", pero desde las páginas o secciones policiales, por practicar lo que cantan en sus temas... ¿ O será a la inversa? Así, en plena caída libre de la fama, y dentro de ciertos límites, "el mal" y las transgresiones, también puede venderse. Entonces, las estrellas que resultaban iconos y modelos para la imitación y emulación de algunos, se transforman en buenos ejemplos de lo que no se debe hacer para todos. El espectáculo no se interrumpe, $y$ las estrellas del delito sirven entonces para enfatizar sobre los valores hegemónicos de la "correcta sociedad".

Las industrias culturales han multiplicado el espectáculo de los medios de comunicación en nuevos espacios, y el espectáculo en sí mismo se hace uno de los principios de organización de la economía, el gobierno, la sociedad y la vida diaria (Kellner, 2003). Omar Rincón (2002:41) dirá que "olvidar que la televisión es una industria es no asumir la complejidad de su naturaleza que indica que es a la vez un medio de expresión, un fenómeno y un negocio".

Por otra parte García Canclini (1993:34) define al consumo cultural como:

El conjunto de procesos socioculturales en que se realizan de apropiación y los usos de los productos, en los que el valor simbólico prevalece sobre el valor de uso y de cambio o donde al menos estos últimos se configuran subordinados a la dimensión simbólica.

Barbero (1987) afirma que, es desde las mediaciones — como "lugar" - desde donde es posible percibir y comprender la interacción entre el espacio de producción y recepción, puesto que lo que se produce en la TV no responde únicamente a requerimientos del sistema industrial y a estrategias comerciales, sino también a exigencias que vienen de la trama cultural $y$ los modos de ver. La TV no funciona sino en la medida en que asume $-y$ al asumir legitima - demandas que vienen de los grupos receptores pero a la vez no puede legitimar esas demandas sin re-significarlas en función del discurso social hegemónico.

Al respecto, dice Jameson (1986:160):

La pobreza urbana puede ser un deleite para la vista cuando se expresa como conversión en mercancía y cómo un salto cuántico sin paralelo en el proceso de alienación de la vida diaria de la ciudad puede ahora experimentarse en forma de un nuevo y extraño regocijo alucinatorio...

Es en la industria musical $y$ de entretenimiento, la obra villera es transformada en mercancía, reduciéndola a un patrón único de estilo. Desde la universalización del símbolo, se destruye el vínculo de identidad del grupo marginado, ya que se constituye en uso general. Se produce así, una inversión del significado del símbolo al separarse del grupo que le dio origen. El símbolo niega su contenido. Pero, analizando las dimensiones culturales de las teorías de comunicación de masa y cultura, Mc Quail (2000:163-164) sostiene que:

La teoría de la bienificación tiene sus orígenes en Marx donde los objetos son con- 
vertidos en bienes al adquirir un valor de intercambio en vez de tener solamente un valor de uso intrínseco. De la misma manera, los productos culturales son producidos y vendidos como bienes en mercados mediáticos. Los consumidores pueden intercambiarlos por satisfacción psíquica, diversión o nociones ilusorias de su lugar en el mundo, lo cual oscurece a menudo las verdaderas estructuras de la sociedad y nuestra subordinación a ella (falsa consciencia): cuanto mayor sea la bienificación del arte o la cultura, mayor será la merma de su potencial crítico.

\section{CONSIDERACIONES FINALES}

La identidad es una construcción relacional e intersubjetiva: emerge y se afirma en la confrontación con otras identidades, lo cual se da frecuentemente en condiciones de desigualdad $y$ por ende, expresando y generando conflictos. Además, es siempre una construcción histórica; debe ser restablecida y negociada permanentemente. En la Argentina, las expresiones periféricas, marginales, han jugado y juegan un papel protagónico en la identidad en los procesos sociohistóricos. Sus actores han sido y son quienes ocupan un lugar obligado en la puesta en escena de prácticas culturales. El lenguaje particular de cada grupo - cargado de evaluaciones sociales, de ideología, de maneras de leer el mundo- ha sido y es el instrumento fundamental para coordinar la acción en contextos permeados por relaciones jerárquicas y binarias, que se filtran en las experiencias biográficas de los sujetos. Una manera de leer ese orden jerárquico y binario de la última década, es a través de la cumbia villera como expresión cultural.

Como el tango "orillero", las letras de la cumbia villera narran similares situaciones de atropellos del sistema, donde siempre está presente el conflicto social. Un sistema que los absorbe desde los medios de comunicación y el mercado, los mastica $y$, hastiado, los regurgita como mercancías a las que ya amortizaron. Precisamente de la emergencia se canta $y$ baila lo que el centro expulsa. Dentro del universo simbólico villero, en la relación individuo-sociedad, será la conciencia la que permita reflexionar sobre las propias acciones, $y$ la conciencia ampliada, para entender y reflexionar sobre la sociedad (Tomasello, 1999).

También en la música villera, sería aplicable aquella máxima de Marx (1859) según la cual no es la conciencia del hombre la que determina su ser sino que, por el contrario, es su ser social el que determina a la conciencia, un sujeto que se autoconoce para poder interrelacionarse con los otros. Esta conciencia histórica-cultural $y$ producto filogenético, que nos permite ser reflexivos sobre nuestras acciones y también, entender $y$ reflexionar sobre la sociedad; que nos distingue de otros seres vivientes $y$ otros periodos históricos-sociales y de las posibilidades de la cultura.

10. ANEXO BREVE GLOSARIO DE LA CUMBIA VILLERA

$\diamond$ Bajar: matar.

\& Bajón: mal momento, síndrome de abstinencia.

$\diamond$ Bicho: pastilla de éxtasis.

\& Birra: cerveza.

$\diamond$ Cannabis: marihuana, porro, yerba, caño, María, María Juana, Mary Jane, falopa, ama, Ramón, boom, pot.

\& Caño: arma de fuego, cigarrillo de marihuana.

$\diamond$ Careta: el que se abstiene de consumir.

\& Cocaína: merluza, merca, lady, dama, polvo blanco, piedra, Blanca Nieves.

\& Champú: champán.

$\diamond$ Descontrol: sinónimo de una situación de diversión exacerbada por el consumo de alcohol o drogas que en algunos casos se presenta con fiesta de fondo.

$\diamond$ Descartar: deshacerse de un arma.

$\diamond$ Duro: calificativo que designa el efecto de rigidez muscular producido por el consumo de cocaína.

$\diamond$ Éxtasis: bicho, pasta.

$\diamond$ Faso/alto faso: cigarrillo de marihuana.

$\diamond$ Flashar/flashear: efecto que produce la droga.

$\diamond$ Fernando: trago que surge de la mezcla de fernet $y$ una gaseosa cola. 
$\diamond$ Fierro: arma de fuego.

$\diamond$ Fija: situación "ideal" para cometer un delito.

$\diamond$ Guardado: preso.

$\diamond$ Jalar: aspirar.

$\diamond$ Lancha: patrullero.

$\diamond$ La yuta: la policía.

$\diamond$ Limado/quemado/volado/fumado: acepciones ligadas al empleo de estupefacientes.

$\diamond$ Línea: modalidad empleada para distribuir el polvo de cocaína para su posterior inhalación.

$\diamond$ Merluza/merca: cocaína.

$\diamond$ Pasta: hipnótico, barbitúrico, sedante, pastilla de éxtasis.

$\diamond$ Pila/de la cabeza: estar drogado.

$\diamond$ Ran: abreviatura de "Poxi-ran", pegamento que se inhala y tiene un efecto alucinógeno.

$\diamond$ Rati /Yuta: policía.

$\diamond$ Ratón: injusto, egoísta.

$\diamond$ Rescatar: salir del síndrome de abstinencia.

$\diamond$ Salir de caño: portación de armas con fines delictivos.

\& Trapo: bandera.

$\diamond$ Tirar humo: fumar un cigarrillo de marihuana.

s Vitamina: cocaína.

\section{ALGUNOS NOMBRES DE LOS GRUPOS} DE CUMBIA VILLERA

1. Bandy2 - bandidos-

2. Corré guachín - avisó que llega la policía-

3. Damas gratis - mujeres a las cuales no hace falta pagarles para tener sexo-

4. Eh guacho - llamado a un par de la villa-

5. El punga - el ladrón callejero, carterista-

6. Flashito tumbero - efecto de drogarse en la cárcel-

7. Gedientos - hedor-

8. La base -alusión a la pasta base de cocaína-

9. La rama - hoja de marihuana-

10. La tisa - piedra de cocaína-

11. Meta guacha - sexo descontrolado-

12. Pibes chorros - muchachos ladrones-

13. Pibex ran - muchachos que se drogan con pegamento sintético (poxirán)—

14. Reempachados - persona llena de excesos-
15. Supermerka2 — super cocaína-

16. Tapuesto —está drogado/borracho-

17. Yerba brava - marihuana-

\section{REFERENCIAS}

Academia Porteña del Lunfardo. "Acerca del termino bailanta". Comunicación Académica nro. 1541 [en línea]. Bs. As., abril de 2001. <http://ar.geocities.com/ lunfa2000/1541.html>

Auyero, J. Otra vez en la Vía. Notas e interrogantes sobre la juventud de los sectores populares. Bs. As., Fundación del Sur. Gecuso. Espacio Editorial. 1993.

Barbero, J. M. "Medios y culturas en el espacio latinoamericano". En: Pensar Iberoamérica. Revista de Cultu-ra Nro. 5. (enero-abril de 2004). Madrid, Organización de los Estados Iberoamericanos para la Educación la Ciencia y la Cultura -OIE-. Ver: $<$ http://www.campus_oei.org/ pensariberoamerica/ric05a01.htm>

- "Identidad, tecnicidad, alteridad: apuntes para trazar el mapa nocturno de nuestras culturas". En: Revista Iberoamericana. Vol. LXIX. Nro. 203, (abril-junio 2003), pp. 367-387.

-. "Globalización y multiculturalidad: notas para una agenda de investigación". Ensayo \& Error. Nro. 3. 1997. Pp. 18-179.

. De los medios a las mediaciones. Comunicación, cultura y hegemonía. México, Gustavo Gilli. 1987.

Barcia, P. L. Diccionario del habla de los argentinos. Academia Argentina de Letras. Bs. As., Espasa. 2003.

Barker, Ch. (2000) Cultural Studies. Theory and Practice. London, SAGE Publications, ( $2^{\text {a }}$ ed.). 2003. 
Benjamin, J. (1988) Lazos de amor. Psicoanálisis, feminismo y el problema de la dominación. Bs. As., Paidós. 1996.

Brunner, J. J., Catalán, C.; Barrios, A. Chile: transformaciones culturales y conflictos de la modernidad 1973-1988. Hacia un nuevo orden estatal en América Latina. Innovación cultural y actores socioculturales. Clacso, Santiago. 1989. Pp. 33-162.

Castoriadis, C. (1975) The Imaginary Institution of Society. Trad. Kathleen Blamey. Cambridge, Massachussets, MIT Press. 1987.

Cerrutti, A y Pitta, C. "Los que bajaron de los barcos: migración ultramarina $y$ prejuicio antiextranjero en la Argentina, 1880-1930”. En: Margulis, M. Urresti, M. et al. (1998) La segregación negada. Cultura y discriminación social. Bs. As. Biblos. 1999.

Danesi, M. (1988) Sign, Thought and Culture: a basic course in semiotics. ( $2^{\circ}$ ed.). Toronto, Canadian Scolars' Press. 2000.

Debord, G. (1967). La sociedad del espectáculo. Madrid, Castellote, (3 ${ }^{\mathrm{a}}$ ed.). 1976.

García Canclini, N. La globalización imaginada. Bs. As., Paidós.1998.

(1991) Posmodernidad en la periferia. Enfoques latinoamericanos de la nueva teoría cultura.l Herlinghous, Hermann y Monika Walter editores. Berlín, Langer.1994.

. "El consumo cultural y su estudio en México: una propuesta teórica". En: García Canclini, Néstor (coord.). El Consumo Cultural en México (Pensar la cultura). ( $1^{a}$ ed.) México, CNCA, Grijalbo, 1993. pp. 15-42.
. Consumidores y ciudadanos. México, Grijalbo. 1992.

. "Los estudios culturales de los 80 a los 90: perspectivas antropológicas y sociológicas en América Latina". Revista de Ciencias Sociales y Humanidades Iztapalapa, UAM, México DF., Año 11, Nro. 24. 1991.

Giddens, A. The consequences of Modernity, California, Stanford University Press, 1990.

Habermas, J. "Modernidad versus Posmodernidad". En: Pico, J. (ed) Modernidad y Postmodernidad. Madrid, Alianza. 1994. Pp.87-103.

. Teoría de la acción comunicativa II: La construcción del mundo de la vida. Buenos Aires, Taurus, 1992.

. Teoría de la Acción Comunicativa: complementos a estudios previos, Madrid, Cátedra. 1989.

. La Acción Comunicativa. Tomo I. Madrid, Taurus. 1987.

Harvey, D. La condición de la posmodernidad: investigación sobre los orígenes del cambio cultural. Bs. As., Amorrortu 1998.

Instituto Nacional de Estadísticas y Censos. "Incidencia de la pobreza e indigencia en el total urbano EPH y por región estadística" [en línea] Buenos Aires. Primer semestre 2004. <http://www. indec.mecon.ar/nuevaweb/cuadros/74/ grafpobreza1_ephcontinua.xls>

Jameson, F. Teoría de la postmodernidad. Madrid, Trotta. 2001.

. "El postmodernismo o la lógica cultural del capitalismo tardío". Revista Casa de las Américas. XxVI. Nro. 155- 
156. La Habana, marzo-junio 1986. Pp. 141-173.

Kellner, D. Media Spectacle. London and New York, Routledge. 2003.

Larraín Ibáñez, J. Modernidad, razón e Identidad en América Latina. Santiago de Chile, Editorial Andrés Bello. 1996.

Lyotard, J. F. La condición posmodernainforme sobre el saber, ( $6^{\circ}$ ed.). Cátedra, Madrid. 1998.

Marx, K. (1859) "Prólogo a la contribución de la Crítica a la Economía Política”. En: Facultad de Sociología de la Universidad de Buenos Aires, Biblioteca Virtual. Apuntes de Investigación cátedra Rubinich 2005. Materiales de Cátedra. Ver: <http://catedras.fscoc.uba.ar/ rubinich/biblioteca/biblio.htm>

Mc. Quail, D. Introducción a la teoría de la comunicación de masas. Barcelona, Paidós. ( $3^{\circ}$ ed.) 2000.

Mead, G. (1934) Espíritu, persona y sociedad. Buenos Aires, Paidós (3ºd.). 1972.

Narodowski, M. "Códigos de la cumbia villera", Miércoles 28 de enero de 2004. Diario Clarín (edición electrónica), Sección Opinión. Nro. 2858. En: <http://www. clarin.com/diario/2004/01/28/o-02301. htm>

Olivier, M. H. "Del Tango al rock se recrea el lunfardo". Portal Informativo sobre la Lengua Castellana Unidad en la diversidad, sección Actualidad. En: <http://www. unidadenladiversidad.com/actualidad/ actualidad_ant/2002/octubre_2002/ actualidad_301002_01.htm>

Rincón, O. Televisión, vídeo y subjetividad. Colombia, Grupo Edit. Norma. 2000.
Rodríguez, M. G. "Representaciones juego incompleto". Ponencia presentada ante las leras Jornadas sobre Representaciones Sociales. "Representaciones sociales: investigaciones y prácticas", Bs. As., Universidad de Buenos Aires. 2003.

Rozenmancher, G. Cabecita negra. Bs. As. De La Flor. 1997.

Salas, H. El tango. Bs. As., Planeta. 1996.

Sánchez Ocampo, C. "Argentina: rostros mixtos y mutantes", Serie Nuevas crónicas sobre la resistencia civil argentina. Fundación Nuevo Periodismo Iberoamericano. Cartagena. 2003. En <http://www. fnpi.org/premio/2003/finalistas/pdf/ 2003CSC1427.pdf>

Sandoval García, C. Otros amenazantes. Los nicaragüenses y la formación de la identidad nacional en Costa Rica. Instituto de Investigaciones Sociales, San José, Universidad de Costa Rica. 2002.

Searle, J. (1979) Actos de habla. Madrid, Cátedra. 1990.

Szwarcer, C. "El conventillo de la paloma un siglo después". Revista Cultural del CECAO. Año II. Nro. XIX, Mayo de 2004, Córdoba, Argentina.

Tomasello, M. "The human adaptation for culture". Annual Review of Anthropology. Nro. 28, pp. 509-530. Palo Alto, California. 1999.

Voloshinov, V. (1929) El marxismo y la filosofía del lenguaje. Madrid, Alianza. 1992.

Williams, R. (1982) Sociología de la cultura. Barcelona, Paidós. 1994.

(1958) Cultura y sociedad 1780-1950. De Coleridge a Orwell. Trad. Horacio Pons. Bs. As., Nueva Visión. 2001. 